\title{
Design and development of copper coatings for long term storage of used nuclear fuel
}

\author{
P. G. Keech*1, P. Vo ${ }^{2}$, S. Ramamurthy ${ }^{3}$, J. Chen ${ }^{3}$, R. Jacklin ${ }^{3}$ and \\ D. W. Shoesmith ${ }^{3}$
}

\begin{abstract}
Within ongoing work, Canada's Nuclear Waste Management Organization (NWMO) is demonstrating that copper coatings can be developed as viable corrosion barriers for used fuel nuclear containers, emplaced in a deep geological repository. As a means of assessing container design and feasibility, coated samples, manufactured via cold spray and electrodeposition have been produced and characterised. Corrosion testing for coated samples and wrought samples reveals that cold spray samples behave similar to wrought samples in $3 \mathrm{~mol} \mathrm{~L}-1$ $\mathrm{NaCl}$ solution at room temperature. When oxygen is absent, corrosion has not been observed.
\end{abstract}

Keywords: Nuclear waste, Copper corrosion, Cold Spray, Electrodeposition, Deep geological repository, Used nuclear fuel

This paper is part of a special issue on 'Long-Term Prediction of Corrosion in Nuclear Waste Systems'

\section{Introduction}

\section{Canada's used nuclear fuel}

The primary challenge associated with management of used nuclear fuel is the timeframe over which components associated with long term storage must perform, which is as long as one million years. The use of copper as an exterior container corrosion barrier has been considered for many years by many national research programs in nuclear waste management, including those in Sweden and Finland, and by Canada's Nuclear Waste Management Organization (NWMO). This is due to its thermodynamic stability in many deep geological repository (DGR) applications, as well as the presence of natural analogues, which include archaeological artefacts $^{1}$ (i.e. coins, cannons, etc.) that contain metallic copper as well as mineral deposits that contain naturally occurring metallic copper. ${ }^{2}$ Figure 1 illustrates a generic schematic of a DGR, including possible horizontal and vertical emplacements of a used fuel container (UFC).

Among the nuclear fuel management organisations considering copper, the primary existing design consists of a two part container, where an inner steel or cast iron insert provides structural support and positions fuel, and an outer copper shell provides a corrosion barrier within the DGR. While manufacturing of such a used fuel container (UFC) is technically feasible and is defined within the NWMO program as a Mark 1 container (see image in Fig. 1), there are manufacturing challenges associated with such a design. Specifically, the need for a narrow gap between the steel insert and copper shell on the order of $1 \mathrm{~mm}$ is a difficult challenge, since it must

${ }^{1}$ Nuclear Waste Management Organization 22 St. Clair Ave E Toronto ON, Canada

${ }^{2}$ National Research Council, 75 Mortagne Blvd Boucherville QC, Canada ${ }^{3}$ Surface Science Western, 999 Collip Cir, London, ON, Canada

*Corresponding author, email pkeech@nwmo.ca be maintained over a container length of $4 \mathrm{~m}$. In addition, the fabrication of an external shell independent of a liner places structural requirements on this component for the purposes of manufacturing and handling; consequently, the thickness of the copper shell must be much greater than is required for corrosion protection. To overcome these issues, NWMO has recently initiated a program to design and develop copper corrosion barriers as coatings or claddings, directly on steel structural components, rather than as a separate component to a UFC. Within the NWMO program, this design is termed Mark II; a representative container is shown in Fig. 2.

While the concept of a copper coating is clearly attractive, significant development is required to ensure that such a process is technologically feasible. In addition to demonstrating an ability to produce the coating using industrially relevant processes, it is necessary to conduct extensive (mechanical) modelling exercises of coated container behaviour within a DGR to ensure it meets the requirements of the safety case. This work is ongoing in other parts of the NWMO program, and will be reported elsewhere. However, regardless of the design, containers that utilise copper as a corrosion barrier must be able to withstand relevant environmental conditions for long periods of time; from a corrosion point of view, NWMO and other organisations have extensively studied this issue.

\section{Copper corrosion in a deep geological repository}

Recent efforts by $\mathrm{NWMO}^{3}$ or independent corrosion experts ${ }^{4}$ have focused on developing and reviewing reasonable corrosion allowances to account for all the processes likely to affect copper materials. In principle, corrosion may occur by a range of mechanisms, including general, localised, stress cracking, microbial induced/microbial influenced, radiation induced and even atmospheric (pre-emplacement) corrosions. The 


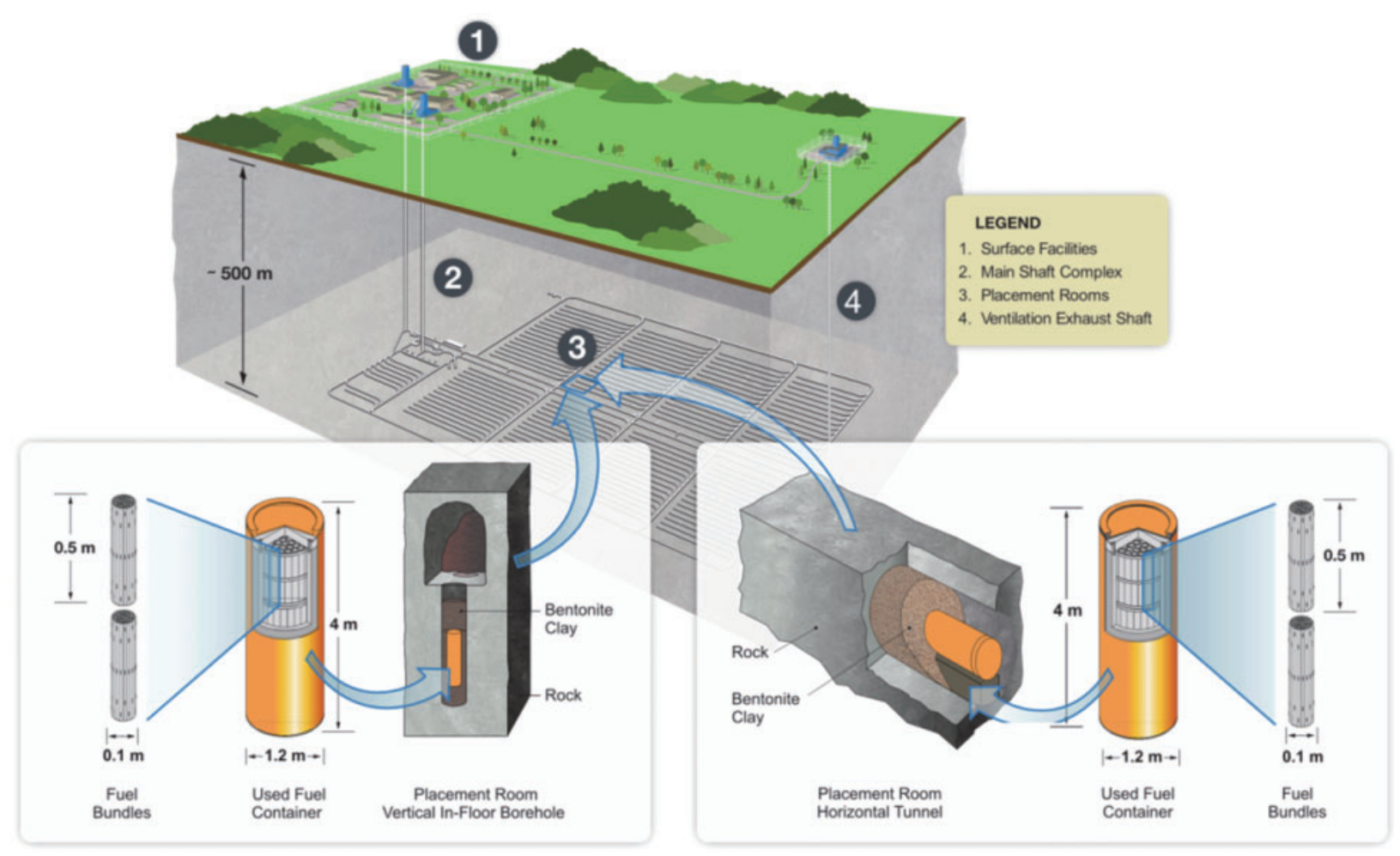

1 Nuclear Waste Management Organization's (NWMO) reference deep geological repository (DGR) concept

environment of and engineered barriers within the DGR serve to minimise these processes such that only very minor corrosion will occur over the life of the UFC. By using mass balance arguments and modelling the processes for a large UFC, general corrosion by oxygen can be contribute at most $0.17 \mathrm{~mm}$ to copper thickness loss. ${ }^{3}$ This conservatively presumes that all oxygen within the repository is consumed by copper corrosion, rather than via steel corrosion (i.e. of rock bolts or other steel construction materials) or microbial consumption. This value increases to $0.27 \mathrm{~mm}$ when considerations are made for surface roughening, as minor surface height variations may occur during this general corrosion reaction. ${ }^{3}$ Radiation/radiolysis related corrosion, a process that decreases as the fuel ages, has shown enhanced effects only at high doses (i.e. $>100 \mathrm{~Gy} / \mathrm{h}$ ); thus this process is not expected within a DGR at the low doses expected to emanate from Canadian UFCs $(\sim 3 \mathrm{~Gy} / \mathrm{h}$ for the reference $30 \mathrm{y}$ old fuel for relatively thin walled containers as depicted in Fig. 2). Subsequent corrosion is expected to be dominated by sulphide related reactions, occurring via the slow movement of sulphide across the bentonite sealing materials. Despite there being no native sulphide in Canadian crystalline ${ }^{5}$

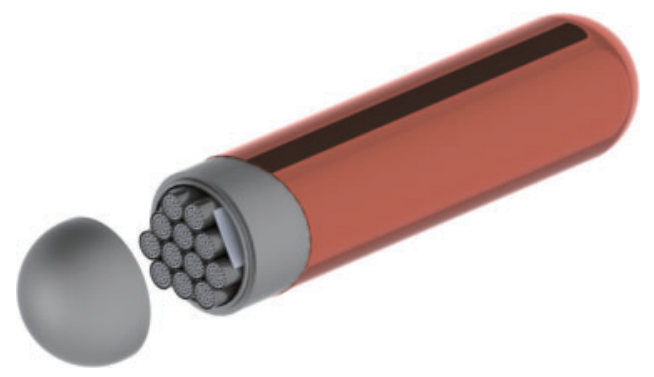

2 Alternative used fuel container design, demonstrating integral copper coating corrosion barrier or sedimentary ${ }^{6}$ groundwaters, NWMO has allowed for remote microbial effects (i.e. microbial sulphate reduction in the far field) impacting the corrosion allowance. Conservatively assuming enough microbial activity could produce a concentration of $3 \mathrm{ppm}$ sulphide (up from the negligible native concentrations of sulphide in Canadian environments) at the buffer-rock interface, a corrosion rate of $1 \mathrm{~nm} /$ year would be realized; this corresponds to $0.1 \mathrm{~mm}$ in one hundred thousand years or $1 \mathrm{~mm}$ in one million years. ${ }^{3}$ Accordingly, extensive review has shown that a copper corrosion allowance of $1.27 \mathrm{~mm}$ is appropriate for one million years storage in a Canadian DGR, and it is acknowledged that much less than $1.27 \mathrm{~mm}$ copper will likely corrode over that time period, owing to the conservative approach to calculating sulphide concentrations. To gain further confidence in this corrosion understanding, NWMO is conducting ongoing work on radiolysis related, aerobic corrosion and sulphide related corrosion over the next several years, particularly as these mechanisms relate to copper corrosion in saline media. Chloride dominated effects are of particular interest in the Canadian sedimentary geosphere, ${ }^{6}$ which may be as high as $30 \%$ sodium chloride; although chloride concentrations exceeding seawater may also be observed for Canadian crystalline geospheres. ${ }^{5}$

\section{Copper coating development and corrosion testing}

Despite the beneficial corrosion properties that copper possesses, several scientific and manufacturing challenges remain prior to the adoption of copper for used nuclear fuel containers (UFCs). To produce a suitable UFC in a timely manner, NWMO has developed a linked program that considers both manufacturing of and corrosion testing of copper. Specifically, this program includes ongoing efforts to produce copper corrosion barriers via coating technologies, and the 
subsequent testing to assess their corrosion performance against wrought copper, which is the corrosion barrier for the dual shell steel-copper container reference design. To that end, NWMO has explored various methods for producing copper coatings on steel; general concepts of cold spray and electrodeposition are described within this work.

\section{Experimental}

\section{Copper coating production}

\section{Cold spray copper deposition developments}

Cold spray involves the acceleration to high velocity of a powder within an inert carrier gas toward a substrate to which it forms a mechanical and/or metalllurical bond. ${ }^{7}$ Very high deposition rates can be obtained by a single gun (i.e. up to $0.5 \mathrm{~kg} \mathrm{~min}^{-1}$ ); however, cold spray has been primarily used as a repair process within other industries. ${ }^{8}$ Within the NWMO program, both low pressure cold spray (LPCS) and high pressure cold spray (HPCS) have been investigated in early work; however, only high pressure cold spray has shown to be a suitable method.

A516 Grade 70 (or similar) steel was prepared by grit blasting with alumina (grit 24) prior to depositing copper; the selection of steel type is based on the NWMO container reference material, rather than expectations regarding coating properties. Subsequently, Plasma Giken PCS-1000 or Kinetiks 4000 cold spray systems were used with nitrogen or helium, respectively, with gas pressures between 2 and $5 \mathrm{MPa}$, gas temperatures between 300 and $800^{\circ} \mathrm{C}$ and spherical and irregularly shaped low oxygen copper powders with mean sizes between 20 and $60 \mu \mathrm{m}$. In some cases, coatings were produced via two stages: initially a $50-100 \mu \mathrm{m}$ bond coat was deposited using helium as a carrier gas, followed by a bulk coating deposited using nitrogen as a carrier gas.

\section{Copper electrodeposition}

As a commercialised process, electrodeposition offers the advantage of coating production on a large scale, including via pulsed plating methods, which was the methodology selected for this process. ${ }^{9}$ It is usually used for thin (i.e. $<0.5 \mathrm{~mm}$ ) coatings, owing to deposition rates that are frequently well below $1 \mathrm{~mm} \mathrm{~h}^{-1}$, which, on a small scale, can translate to as little as a few $\mathrm{mg} \mathrm{h}^{-1}$. However, because deposition rates are based on current densities, scaling to large surface area can produce deposition rates which can exceed many tens of $\mathrm{kg} \mathrm{h}^{-1}$, presuming an even current distribution across a UFC.

To minimise carbon and oxygen content within the copper coating, pyrophosphate was used as the primary bath component, and pulsed potentiometry was used to apply sufficient current. ${ }^{9}$ A high purity, oxygen free copper anode was used as the copper source; the process involved oxidative dissolution of the anode and subsequent reductive plating of the copper ions onto the steel substrate.

\section{Copper coating corrosion properties}

Once coating techniques had been preliminarily optimised, selected samples were submitted to corrosion analysis. In general, this analysis consisted of: solution exposure tests, where various oxygen amounts were used; electrochemical impedance spectroscopy (EIS), and polarisation tests. Owing to limitations of space and the scope of this article, EIS and polarisation test results are not included in this paper and will be published elsewhere. Experiments were conducted in three conditions: in an anaerobic chamber (no oxygen); on the bench top, with continuous argon purge (trace oxygen); and on the bench top with one month of continuous oxygen purge, followed by two months of continuous argon purge (trace oxygen). $3 \mathrm{~mol} \mathrm{~L}^{-1} \mathrm{NaCL}, \mathrm{pH}$ neutral solutions were used at room temperature for these analyses. Data were obtained on Solartron Equipment (287 Potentiostat connected to 1250/1255B frequency analyzers for EIS analysis), controlled by Scribner (SAI and Associates, version 3.1) software.

\section{Copper coating material characterisation \\ Mechanical analysis of copper coatings}

During the preparation of copper coatings, a series of mechanical tests were performed, for which publications are forthcoming. ${ }^{10}$ Included in these assessments were microhardness (e.g. via ASTM-B578 on cross-sections, to assess changes with respect to coating thickness), adhesion (via the cold spray specific ASTM-C633, various bend testing and chisel testing, ASTM-B571 and modified ASTM-E8 tensile tests), tensile testing (via ASTM-E8). This extensive work cannot be presented within this paper; however, results are noted where a specific result is deemed useful in the context of this article.

\section{Surface and cross-sectional analysis of copper coatings}

During optimisation of coated samples, the material surfaces were extensively analysed using many methods, including scanning electron microscopy/energy dispersive X-ray spectroscopy (SEM/EDX), optical microscopy, electron backscatter diffraction (EBSD) and X-ray photoelectron spectroscopy (XPS). Specifically, surface analyses (XPS, SEM-EDX) were used to validate an absence of (bath) phosphate materials in the finished electrodeposition coating, as well as search for any trace contaminants in both cold spray and electrodeposition samples (i.e. sulphur, carbon, oxygen). Surface analysis results from optimization work are presented elsewhere, ${ }^{10}$ only representative SEM or optical images will be described herein. To complement corrosion testing, surface analysis was repeated at the conclusion of exposure tests described below; thus, any changes that occurred as a result of corrosion could be measured.

\section{Wrought copper assessment}

Along with the copper coated samples, wrought copper samples were subjected to the corrosion and, where applicable, to the material characterisation tests indicated above. Two forms of copper were used: highly pure oxygen free copper C10100, (Alpha Aesar) and a similar oxygen free grade, ('SKB copper', doped with nominally 30-100 ppm phosphorus, for improved creep ductility, and for which extensive research exists ${ }^{11}$ ).

\section{Results and discussion}

\section{Copper coating development results Cold spray copper}

Figure 3 illustrates selected characterisations of the cold spray materials: including (a) SEM of a typical powder 


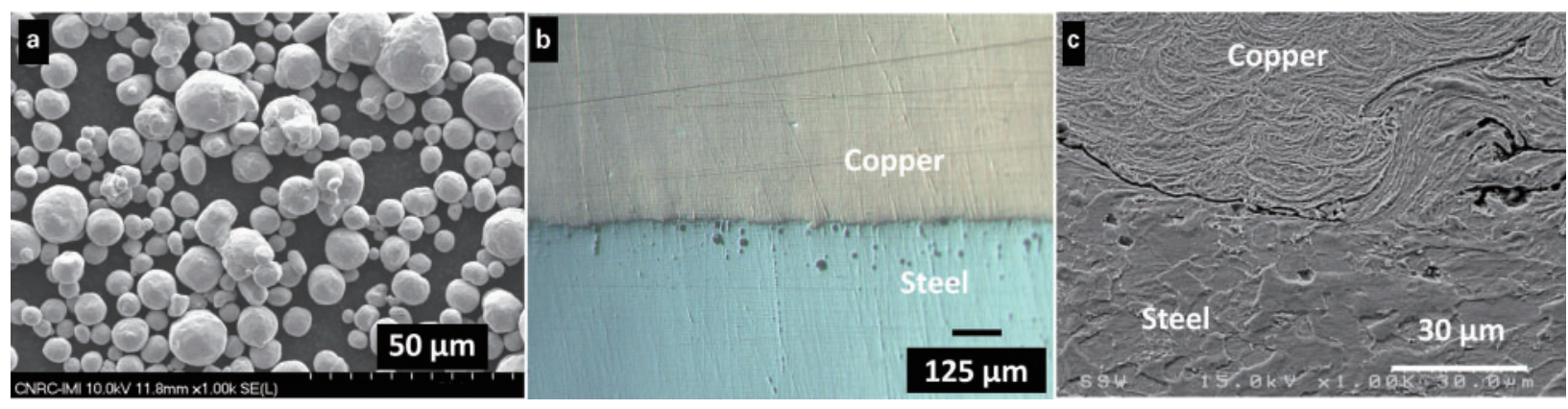

3 a SEM of typical low oxygen copper powder used for cold spray deposition; cross-sectional copper cold spray sample imaged via, $b$ optical and $c$ SEM (of etched sample)
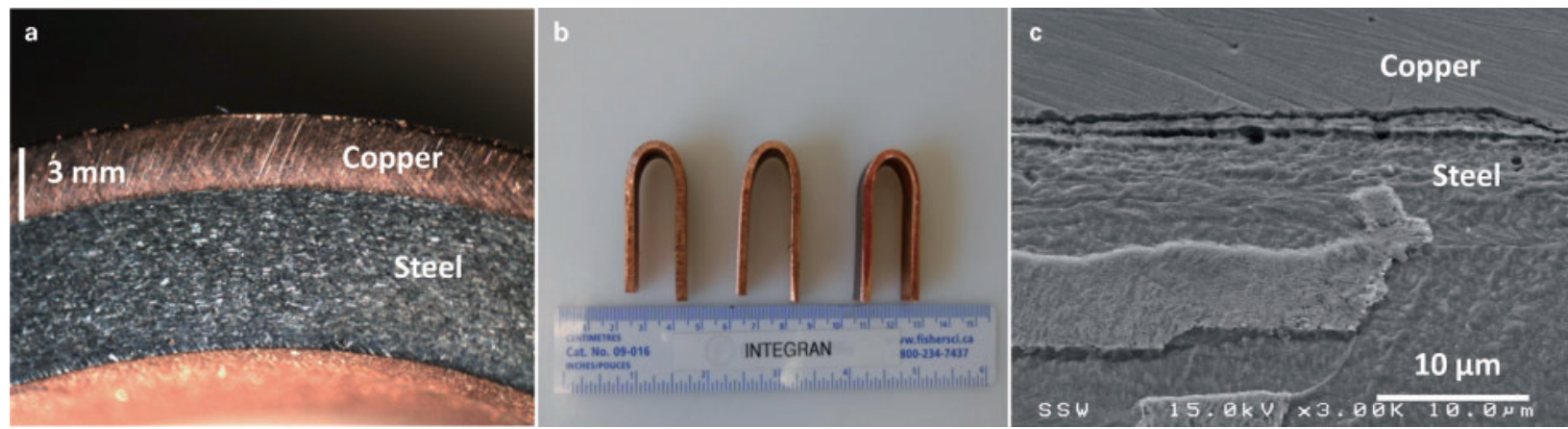

4 Images of electrodeposited sample showing a close up of steel/copper interface (via optical imaging), $b$ results of bend test for $15 \mathrm{~cm}$ long, $3 \mathrm{~mm}$ thick coating samples heated (from left to right) to $25^{\circ} \mathrm{C}$ (i.e. as deposited), $60^{\circ} \mathrm{C}$ and $120^{\circ} \mathrm{C}$ (via optical imaging) and $c$ etched cross section (via SEM)

shape/size utilised in cold spray (CS) coatings; (b) the optical image of the interface; and (c) an SEM of the intimate mixing between the copper coating and steel substrate, a process termed jetting. Where this feature is observable, coatings tend to be adhered well onto the substrate.

Extensive analysis was performed on a wide range of coatings with the goal of defining suitable reference coating parameters. As a result of the extensive effort, NWMO has defined that as deposited copper cold spray samples can effectively be produced using nominal settings of:

(i) $10-70 \mu \mathrm{m}$ spherical low oxygen copper powder

(ii) minimum 1' A 516/grade 70 steel, grit blasted with 24 grit to remove millscale

(iii) $100 \mu \mathrm{m}$ bond coat (see below), applied with $\mathrm{He}$ at $5 \mathrm{MPa}$ and $800^{\circ} \mathrm{C}$

(iv) $3 \mathrm{~mm}$ top coat, applied with $\mathrm{N}_{2}$ at $5 \mathrm{MPa}$ and $800^{\circ} \mathrm{C}$.

The use of the He 'bond coat' allows for enhanced adhesion of the copper to the steel substrate, as the particle velocity exceeds $900 \mathrm{~m} \mathrm{~s}^{-1}$; subsequent deposition via $\mathrm{N}_{2}$ occurs with a lower particle velocity $\left(\sim 700 \mathrm{~m} \mathrm{~s}^{-1}\right)$. As expected,,$^{12}$ as deposited samples have very little ductility; generally $1-2 \%$ elongation at fracture was observed for samples within the NWMO program, as measured in standard tensile testing via ASTM-E8. ${ }^{13}$ Preliminary results indicate that annealing at $600^{\circ} \mathrm{C}$ achieves ductility comparable to wrought copper; optimisation of this heat treatment cycle is underway.

\section{Copper electrodeposition}

Figures $4 a-c$ illustrate electrodeposited copper samples obtained within the NWMO program. In general, these samples exhibited a good combination of high tensile strength and hardness, in addition to ductility. These characteristics did not require post deposition heat treatment to produce the $3 \mathrm{~mm}$ coating (Fig. $4 a$ ). During bend tests (Fig. $4 b$ ), the coating performed very well, adhering with no delamination occurring. Companion tensile tests via ASTM-E8 revealed elongation values in excess of $30 \%$ prior to fracture (not shown). Deposition rates for this process were not rapid, as the $3 \mathrm{~mm}$ coating took more than 2 days to produce. However, the nature of the process allows for this time to be constant regardless of the dimension of material being coated (i.e. either small plates or an entire container can be coated in the same 2 day time period, a feat being explored in current work programs). Figure $4 c$ illustrates the SEM cross-section; no porosity can be observed within this sample; the fine particle structure of the copper cannot be observed, even after etching.

As with the cold spray coating, a reference parameter coating was defined within the electrodeposition program, allowing for a very pure copper coating, with low oxygen $(<50 \mathrm{ppm})$ to be produced. However, at this point, the maximum amount of oxygen allowable within the copper has not been defined; results from the corrosion assessment in future experiments will guide any such value for oxygen content. Should a higher allowable value be used, it is likely that significant deposition rate increases could be observed (i.e. by a factor of up to two); this topic will also be investigated in the future.

\section{Coating corrosion testing}

As indicated above, selected coupons were submitted to a corrosion testing protocol, in conjunction with tests 

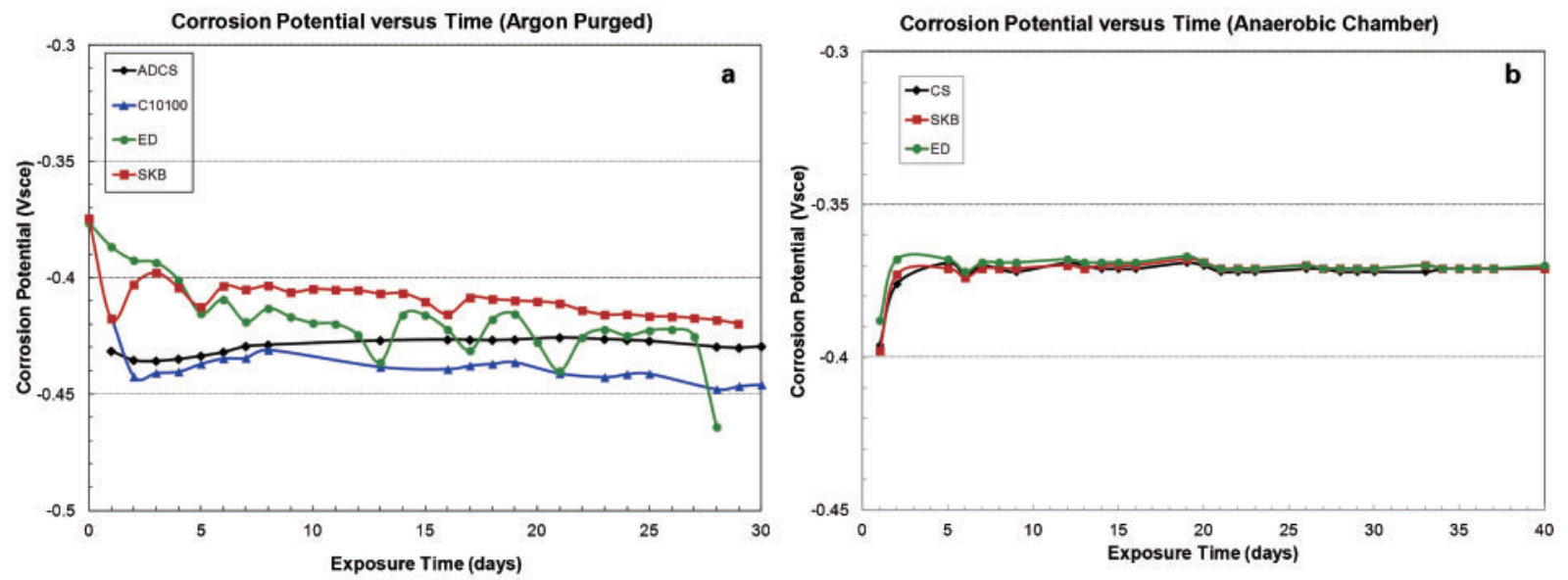

5 Electrochemical potential measurements of coppers exposed to $3 \mathrm{~mol} \mathrm{~L}^{-1} \mathrm{NaCl}$ for $30-40$ days, as noted: a as deposited cold spray (ADCS); polished high purity (C10100); as deposited electrodeposited (ED); and polished SKB wrought (SKB) in argon purged solutions (i.e. with trace oxygen); and b polished cold spray (CS), polished electrodeposited (ED), polished SKB wrought (SKB) in anaerobic chamber (i.e. oxygen-free)

performed on wrought copper specimens. Results in this paper are both preliminary and part of a larger investigation; more extensive results and corrosion testing methods will be reported elsewhere.

\section{Exposure tests}

To allow for testing in different corrosion conditions, the oxygen level was varied for three sets of experiments, from (virtually) no oxygen in an anaerobic chamber, low oxygen (argon purged on the bench top) and high oxygen (oxygen purged for 1 month on the bench top). In general, electrochemical measurements revealed consistent behaviour among the 'as deposited cold spray' (ADCS), electrodeposited (ED) and wrought (C10100 and SKB) samples. As an example, Fig. $5 a$ illustrates corrosion potential measurements obtained during $\left(3 \mathrm{~mol} \mathrm{~L}{ }^{-1} \mathrm{NaCl}\right)$ solution exposure tests conducted in argon purged benchtop experiments; results are shown for 30 days. As noted above, these conditions are nominally anaerobic, but do allow trace amounts of oxygen to enter the cell via diffusion. Similar results have been obtained within an anaerobic chamber Fig. $5 b$ for 40 days, where oxygen control is even greater. In both cases, highly consistent results were obtained among the samples; in the latter case, where oxygen is absent, results were particularly consistent, and did not show the small variation that can be observed in the argon purged experiments that allow for trace oxygen. The argon purged experiments also demonstrated an early decrease in potential, which may be caused by a minor build up of oxygen prior to exposure (i.e. up to about $8 \mathrm{ppm}$, and slightly less as oxygen is consumed); however, this is not confirmed. While preliminary, these results are compelling in that they demonstrate copper coatings perform equivalently to wrought copper forms.

\section{Surface analysis of exposed samples}

Following exposure, the surfaces were analysed and compared with initial conditions. Figure 6 displays SEM images demonstrating the effect of exposure environments, as noted. Clearly, as the oxygen level is increased (i.e. $b \rightarrow d, f \rightarrow h, j \rightarrow l$ ), additional corrosion occurs, as the corrosion product clusters are more visible. This is true for all copper forms, thus it can be observed within any row (CS, ED SKB copper, in order). In addition, direct comparison between the first two images of any row suggests that no measurable corrosion occurs during the 90 day anaerobic exposure; again, this is true for all copper forms. Slight oxidation observed among samples from argon purged experiments. Figure $6 c, g$ and $k$ for CS, ED and SKB respectively, have the same general structure, in that there is a light decoration of nodular oxides on the surfaces. Nodular growth is increased when oxygen is intentionally added. Figure $6 d, h$ and $l$ reveal similar oxide features for CS, ED and SKB coppers, and there was an absence of localised corrosion among the samples as well, at least on the scale of resolution of the SEM.

Complementary surface analyses (i.e. X-ray photoelectron spectroscopy, Raman spectroscopy, not shown) as well as phase identification (X-ray diffraction) have revealed no tangible differences between the wrought, electrodeposited and cold spray samples, following exposure tests. Extensive ongoing work is probing questions regarding localized corrosion, humidified air corrosion and galvanic corrosion to further build confidence in the corrosion performance of coated samples. This work will be presented in future publications.

\section{Conclusions}

The newly initiated copper coating program at NWMO has produced some encouraging results regarding fabrication of copper corrosion barriers for UFCs. Cold spray and electrodeposition derived coatings can be rapidly applied to steel substrates; these methods produce controllable copper layers of uniform thickness. Corrosion testing has also demonstrated that these barriers perform similar to wrought copper, which is the reference container material.

\section{Acknowledgements}

Experiments have been conducted at Western University, Integran Technologies Inc, National Research Council 


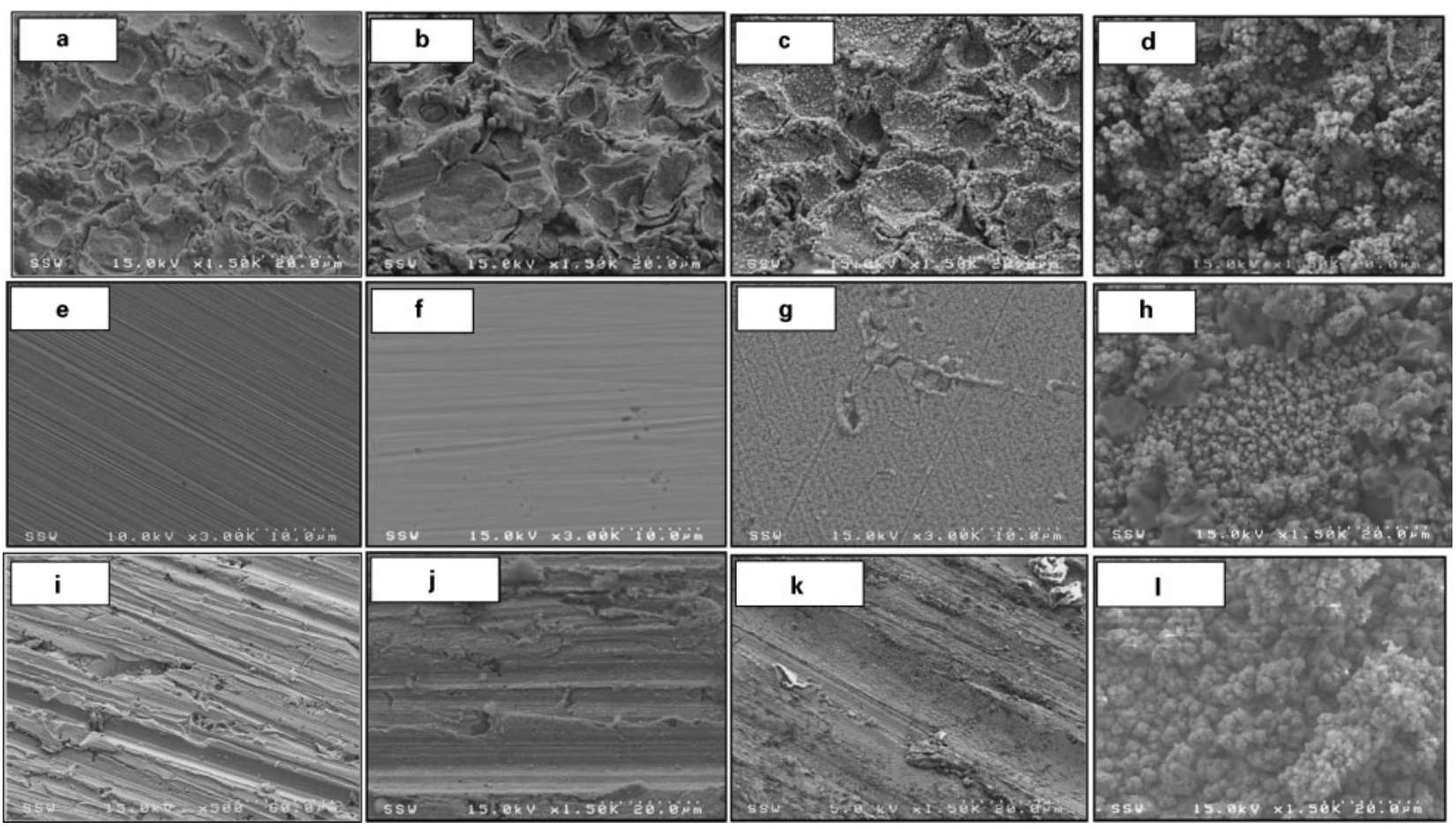

6 SEM images (note changes of scale) of cold spray samples: $a$ as deposited; $b$ post $90 \mathrm{~d}$ exposure to anaerobic chamber; $c$ post $90 \mathrm{~d}$ exposure to Ar purging on bench top and $d$ post $30 \mathrm{~d}$ exposure to $\mathrm{O}_{2}$ purging, followed by $60 \mathrm{~d}$ exposure to Ar purging on bench top; electrodeposited samples: $e$ as polished; $f$ post $90 \mathrm{~d}$ exposure to anaerobic chamber; $g$ post $90 \mathrm{~d}$ exposure to Ar purging on bench top and $h$ post $30 \mathrm{~d}$ exposure to $\mathrm{O}_{2}$ purging, followed by $60 \mathrm{~d}$ exposure to Ar purging on bench top; wrought samples: $i$ as polished; $j$ post $90 \mathrm{~d}$ exposure to anaerobic chamber; $k$ post $90 \mathrm{~d}$ exposure to Ar purging on bench top and $I$ post $30 \mathrm{~d}$ exposure to $\mathrm{O}_{2}$ purging, followed by $60 \mathrm{~d}$ exposure to Ar purging on bench top

(Boucherville) facilities. Nagra has contributed financially to this program.

\section{References}

1. F. King: 'A natural analogue for the long-term corrosion of copper nuclear waste containers - reanalysis of a study of a bronze cannon', Appl. Geochem., 1995, 10, 477.

2. M. L. Chastain, A. C. Deymier-Black, J. E. Kelly, J. A. Brown and D. C. Dunand: 'Metallurgical analysis of copper artifacts from Cahokia', J. Archaeol. Sci., 2011, 38, 1727.

3. G. M. Kwong: 'Status of corrosion studies for copper used fuel containers under low salinity conditions', NWMO Technical Report, NWMO-TR-2011-14, Nuclear Waste Management Organization, Toronto, Canada, 2011.

4. J. R. Scully and M. Edwards: 'Review of NWMO copper corrosion allowance', NWMO technical report, NWMO-TR-2013-04, Nuclear Waste Management Organization, Toronto, Canada, 2013.

5. J. McMurry, B. M. Ikeda, S. Stroes-Gascoyne, D. A. Dixon and J. D. Garroni: 'Evolution of a Canadian deep geologic repository: defective container scenario', Ontario Power Generation Report 06819-REP-01200-10127-R00, Toronto, Canada, 2004.

6. INTERA: 'Descriptive Geosphere Site Model. Prepared by Intera Engineering Ltd. for the Nuclear Waste Management Organization', NWMO DGR-TR-2011-24, Toronto, Canada, 2011.
7. E. Irissou, J.-G. Legoux, A. Ryabinin, B. Jodoin and C. Moreau: 'Review on cold spray process and technology: Part I-intellectual property', J. Therm. Spray Technol., 2008, 17, 495.

8. J. Villafuerte and D. Wright: 'Practical cold spray success: repair of $\mathrm{Al}$ and $\mathrm{Mg}$ alloy aircraft components', Adv. Mater. Proc., 2010, 168, 53.

9. K. Aust, I. Brooks, F. Gonzalez, P. Lin, G. Palumbo, K. Tomantschger and N. Nagarajan: 'Method for preparing polycrystalline structures having improved mechanical and physical properties', Canadian Patent No. 2674403, 2008.

10. P. Vo, D. Poirier, J.-G. Legoux, P. G. Keech and E. Irissou: 'Application of copper coatings onto used fuel canisters for the canadian nuclear industry,' Applications of High Pressure Cold Spray Technology, ASM International (Materials Park, OH), to be published.

11. R. Sandström and H. C. M. Andersson: 'The effect of phosphorus on creep in copper', J. Nucl. Mater., 2008, 372, 66.

12. P. D. Eason, J. A. Fewkes, S. C. Kennett, T. J. Eden, K. Tello, M. J. Kaufman and M. Tiryakioglu: 'On the characterization of bulk copper produced by cold gas dynamic spray processing in as fabricated and annealed conditions', Mater. Sci. Eng. A, 2011, A258, 8174 .

13. Standard Test Methods for Tension Testing of Metallic Materials, ASTM E8/E8M-08, ASTM International, West Conshohocken, USA, 2008. 